Jorg, M. E. (1935). Reun. Soc. argent. Pat. reg., 3, 1563.

Jutzy, D. A., Biber, S. H., Elton, N. W., and Lowry, E. C. (1953). Amer. J. trop. Med. Hyg., 2, 129.

Lamb, G. (1904), Lancet, $2,1273$.

Laurent, L. J. M., and Parish, H. J. (1952). British Medical Journal, 1, 1294. Littlewood, A. H. M., Mant, A. K., and Wright, G. P. (1954). Ibid., 2.
444.

Martin, C. J. (1907). In T. C. Allbutt and H. D. Rolleston's System of Medicine, 211, 783. London.

Miller, H. G., and Stanton, J. B. (1954). Quart. J. Med., 23, 1.

Minton, S. A. (1950). Proc. Indiana Acad. Scl., 60, 315.

(1952). Quart. Bull. Indiana Univ. med. Center, 14, 1

M'Kenzie (1820). Asiat. Res., 13, 329.

Pacheco e Silva, A. C. (1933). Rev. sud.-amer. Méd. Chir., 4, 429.

Reid, C. C., and Flecker, H. (1950). Med. J. Aust., 1, 82.

Reid, H. A. (1956). Trans. roy. Soc. trop. Med. Hyg., 50, 517

Savoor, S. R. (1955). Rep. Inst. med. Res., Fed. Malaya, No. 45, p. 15.

Shannon, F. A. (1953). Sthwest. Med., 34, 367

Swaroop, S., and Grab, B. (1954). Bull. Wld Hith Org., 10, 35.

Tidswell, F. (1906). Researches on Australian Venoms. Govt. Printer, Sydney.

Watt, H. F., Parrish, H. M., and Pollard, C. B. (1956). N. C. med. J.,

Williams, D. A. (1955). British Medical Journal, 1, 1469.

\section{$\phi_{\text {SYSTEMIC TREATMENT OF }} \overline{\overline{\text { TRICHOMONAL }}}$ TRICHOMONAL INFECTIONS}

\author{
BY
}

R. D. CATTERALL, M.R.C.S., L.R.C.P.

Registrar to the Whitechapel Clinic, London Hospital

AND

C. S. NICOL, M.D., M.R.C.P.

Physician in Charge, Special Treatment Centre, St. Thomas's Hospital, London

It is generally agreed that the treatment of trichomonal infections is unsatisfactory. The claims made for various therapeutic agents are frequently conflicting, and this may be due to varying standards of diagnosis and criteria of cure as well as to faulty assessment arising from a high incidence of defaulters and difficulty in arranging a satisfactory series of controls. Recent work has established the fact that the parasite is often present in the urinary tracts of both male and female patients (Kean, 1955 ; Whittington, 1956, personal communication), and it seems reasonable to suppose that reinfection of the vagina after apparently successful local treatment may occur from this source. The ideal remedy for the disease would be a drug which would be effective when administered systemically and so would eradicate the parasite not only from the vagina in women and the urethra in men but also from other parts of the genitourinary tract not accessible to local treatment. The investigation and treatment of sexual partners is also essential to eliminate another possible source of reinfection.

Recently claims have been made for two drugs which are said to be effective when administered by mouth. The object of this investigation was to test these claims and assess the place of these preparations in the treatment of trichomonal infections.

The first of these drugs was " trichomycin," an antibiotic isolated from Streptomyces hachijoensis in Japan by Hosoya et al. (1950, 1952). Reports from Japan indicated that it was effective against trichomonads both in vitro and in vivo. It was also claimed to be effective against Candida albicans (Magara et al., 1955). Shortly afterwards another preparation, acinitrazole (2-acetylamido-5-nitrothiazole ; "tritheon "; " trichorad"), was used in the United States (Cuckler et al., 1955) and claimed to be effective when given by mouth in the treatment of trichomonal infections (Plentyl et al., 1956).
Previously Bushby and Copp (1955) had demonstrated that certain of the amido-nitrothiazoles were more active in vitro against Trichomonas vaginalis than acetarsol ; and Bushby, Catterall, and Williamson (1955) had shown that forminitrazole (2-formamido-5-nitrothiazole), a related compound, was effective in suppressing symptoms and causing the parasite to disappear rapidly when used as vaginal pessaries.

\section{Diagnosis and Tests of Cure}

In cases in the female, diagnosis was established by examination of wet smears and by cultures of vaginal secretions. Specimens of vaginal exudate were obtained, using the vaginal spoon method described by Jackson et al. (1948). Some of this material was inoculated into tubes of the liquid liver medium of Feinberg and Whittington (1957, in press). Samples of urine were obtained and the centrifuged deposit was examined microscopically and cultured in the same medium. In cases in the male, urethra scrapings were examined by dark-ground microscopy and cultures were also made. Centrifuged deposit of urine was also examined microscopically and cultures were taken. The patients were re-examined in the middle of the course of treatment and at the end of treatment, and the same tests applied. Samples of urine were obtained from a small number of patients on the last day of treatment and the antitrichomonal effect of the urine was assayed against standard cultures of trichomonads. In a few cases samples of blood serum were obtained before, during, and at the end of treatment, and the trichomonacidal effect was assayed. In many of the cases the blood haemoglobin was estimated and total white and differential cell counts were made before and after treatment.

\section{Trichomycin}

The first available supplies of trichomycin were in the form of vaginal pessaries containing 50,000 units of the antibiotic in each pessary. In-vitro tests of this substance against a standard culture of trichomonads showed that it was actively trichomonacidal in low concentration (Table I) and that its activity compared favourably with that of acetarsol (Table II).

\begin{tabular}{|c|c|c|c|c|c|c|c|}
\hline \multirow{2}{*}{\multicolumn{2}{|c|}{$\underset{\text { Concentration }}{\text { Final }}$}} & \multicolumn{2}{|c|}{ After 1 Hour } & \multicolumn{2}{|c|}{ After 6 Hours } & \multicolumn{2}{|c|}{ After 24 Hours } \\
\hline & & $\begin{array}{l}\text { Micro. } \\
\text { Exam. }\end{array}$ & Culture & $\begin{array}{l}\text { Micro. } \\
\text { Exam. }\end{array}$ & Culture & $\begin{array}{l}\text { Micro. } \\
\text { Exam. }\end{array}$ & Culture \\
\hline $\begin{array}{c}5,000 \\
500 \\
50 \\
5\end{array}$ & $\begin{array}{l}. \\
\because \\
\therefore\end{array}$ & $\begin{array}{l}\dot{+} \\
+ \\
+ \\
+\end{array}$ & $\begin{array}{l}\bar{z} \\
\overline{+} \\
+\end{array}$ & $\begin{array}{l}- \\
\bar{t} \\
+ \\
+\end{array}$ & $\begin{array}{l}\overline{-} \\
\bar{t} \\
+\end{array}$ & $\begin{array}{l}\overline{-} \\
\bar{t} \\
+\end{array}$ & $\begin{array}{l}\bar{z} \\
\bar{t}\end{array}$ \\
\hline
\end{tabular}

TABLB II.-In-vitro Tests with Acetarsol

\begin{tabular}{|c|c|c|c|c|c|c|c|}
\hline \multirow{2}{*}{\multicolumn{2}{|c|}{$\underset{\text { Final }}{\text { Concentration }}$}} & \multicolumn{2}{|c|}{ After 1 Hour } & \multicolumn{2}{|c|}{ After 6 Hours } & \multicolumn{2}{|c|}{ After 24 Hours } \\
\hline & & Micro. & Culture & Micro. & Culture & Micro. & Culture \\
\hline $\begin{array}{c}10 \mathrm{mg} . / \mathrm{ml} . \\
2 \quad " \\
1 \quad "\end{array}$ & $\begin{array}{l}\because \\
\therefore\end{array}$ & $\begin{array}{l}+ \\
+\end{array}$ & $\begin{array}{l}+ \\
+ \\
+\end{array}$ & $\stackrel{+}{+}$ & $\begin{array}{l}\bar{t} \\
+\end{array}$ & $\bar{t}$ & $\dot{t}$ \\
\hline
\end{tabular}

Twenty-three women were treated, each by the vaginal insertion of one pessary of trichomycin every night for 14 nights. As controls, 23 patients were treated with acetarsol, using two pessaries nightly for 14 nights. Eleven patients defaulted, of whom five were receiving trichomycin and six acetarsol. The remainder were followed for three months. Trichomonads disappeared from the vaginal secretions rapidly in both groups, but subjective relief of symptoms was more rapid in the group treated with acetarsol. One patient receiving trichomycin complained of vulval and vaginal soreness but completed the course of treatment. After followup for three months 17 of the patients treated with trichomycin had relapsed, eight of them within the first three 
weeks following treatment. On the other hand, only eight of the patients treated with acetarsol had relapsed (Table III).

Ten women were treated systemically by giving one trichomycin tablet of 5,000 units orally three times a day for 10 days. In 9 of the 10 cases trichomonads were found in the urine before treatment, by microscopical and cultural methods. In all 10 cases trichomonads were found in the vaginal secretion, before, during, and at the completion of

TABLE III.-Results of Treatment with Trichomycin

\begin{tabular}{|c|c|c|c|c|}
\hline Dosage & $\begin{array}{c}\text { No. } \\
\text { Treated }\end{array}$ & Cures & Failures & Defaulters \\
\hline 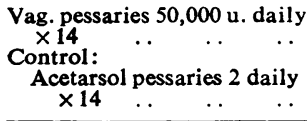 & 23 & 9 & 17 & 5 \\
\hline 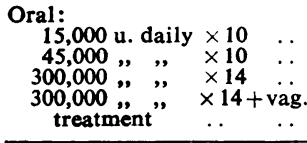 & $\begin{array}{r}10 \\
4 \\
26 \\
4 \\
4\end{array}$ & $\begin{array}{l}0 \\
0 \\
0 \\
0\end{array}$ & $\begin{array}{r}10 \\
4 \\
23 \\
4 \\
4\end{array}$ & $\begin{array}{l}0 \\
0 \\
3 \\
0 \\
\end{array}$ \\
\hline Total & 44 & 0 & 41 & 3 \\
\hline
\end{tabular}

and after treatment. Samples of urine were examined for trichomonacidal activity on the last day of treatment in four cases and all were found to be without such activity.

The dose of trichomycin was then increased to 15,000 units three times a day for 10 days. Four patients (two men and two women) were so treated. In none of these cases was any therapeutic effect apparent, and trichomonads were present in the urine or in urethral or vaginal secretions throughout the period of treatment.

In view of these disappointing preliminary results, the dosage was increased to 300,000 units a day given in the form of two tablets, each of 50,000 units three times a day for 14 days. Twenty women were treated with this dosage ; 2 defaulted during treatment and 17 failed to respond to treatment, trichomonads being found in the vaginal secretions during and at the end of treatment. In the other case there were no trichomonads in the vaginal secretions at the end of treatment, but the patient then discontinued attendance. Six men suffering from trichomonal urethritis, of whom four were contacts of women under treatment, were also treated with 300,000 units of trichomycin daily for 14 days. In all six cases trichomonads were found in the urine and in urethral scrapings during and at the completion of treatment (Table III).

Samples of urine were obtained on the final day of treatment from 18 patients who had taken 300,000 units of trichomycin daily for 14 days (total dose 4,200,000 units). The urine was tested against a culture of $T$. vaginalis in 8 cases and against a culture of $C$. albicans in 10 . No antitrichomonal or antimonilial effect was observed in any of the samples of urine. Samples of blood serum obtained from six patients, before, in the middle of, and at the end of treatment were examined for antitrichomonal activity, and in none of the samples was any increased antitrichomonal activity detected.

Four women were treated with combined systemic and local trichomycin, each receiving 300,000 units of trichomycin daily by mouth for 14 days and one vaginal pessary containing 50,000 units inserted each night for 14 nights. All four patients had trichomonads present in the urine before treatment. The organism disappeared from the vaginal secretions during treatment but was still demonstrable in the urine by cultural methods. At the end of one month all four patients had relapsed with trichomonads present in the vagina.

It thus appears that trichomycin, although active against $T$. vaginalis in vitro, had no therapeutic activity when given systemically in high doses. Local vaginal treatment suppressed the infection temporarily, but relapses were very frequent. Serious toxic effects were not found. No anti- trichomonal or antimonilial activity was observed in the urine after doses of over 4 million units, and no increased antitrichomonal activity was discovered in the blood serum after similar doses. It is probable, therefore, that the drug is either not absorbed from the intestine or that it is metabolized in the body to an inactive compound.

\section{Acinitrazole}

This product is already available to physicians in several countries and has been widely advertised in the medical press. It is presented in enteric-coated tablets each containing $100 \mathrm{mg}$. of the active principle. The dose recommended by the manufacturers is one $100-\mathrm{mg}$. tablet three times daily after meals for 10 days.

In the first trial 10 women suffering from trichomonal infections were treated with the drug in this dosage for 10 days, and a control series of 10 women received one 5-gr. $(300-\mathrm{mg}$.) tablet of calcium lactate by mouth three times daily for 10 days. In all 20 cases trichomonads were present in the vaginal secretions throughout treatment and after the completion of treatment. One patient receiving acinitrazole tablets complained of nausea and abdominal pain during treatment, which was therefore discontinued. No significant changes in the haemoglobin or white cells of the blood were noted in any of the patients at the end of the course of treatment.

It was suggested by one of the manufacturers of acinitrazole that this drug should be used concurrently with local treatment with "penotrane" (phenylmercuric dinaphthylmethane disulphonate) in vaginal pessaries. Accordingly nine women were treated with $100 \mathrm{mg}$. of acinitrazole by mouth three times daily for 10 days and one penotrane pessary vaginally twice daily. All but one of these patients relapsed within one week of completing treatment and the remaining patient defaulted after one week of follow-up (Table IV).

TABLE IV.-Results of Treatment with Acinitrazole

\begin{tabular}{|c|c|c|c|c|}
\hline Dosage & $\begin{array}{c}\text { No. } \\
\text { Treated }\end{array}$ & Cures & Failures & Defaultor \\
\hline $\begin{array}{l}\text { Control: } \\
\text { Cal. lactate } 3 \text { tabs. daily } \\
\times 10 \quad \ldots \quad \ldots \quad \ldots\end{array}$ & 10 & 0 & 10 & 0 \\
\hline $\begin{array}{l}300 \mathrm{mg} \text {. daily } \times 10 \\
300 \text {. } \\
\text { trane pessaries }\end{array}$ & $\begin{array}{r}26 \\
9\end{array}$ & $\begin{array}{l}0 \\
0\end{array}$ & $\begin{array}{r}26 \\
8\end{array}$ & $\begin{array}{l}0 \\
1\end{array}$ \\
\hline Total & 35 & 0 & 34 & 1 \\
\hline
\end{tabular}

Finally, 16 patients ( 6 men and 10 women) were treated with acinitrazole in dosage of $100 \mathrm{mg}$. three times daily for 10 days. No controls were used in this series in view of the uniformly poor results obtained earlier. Trichomonads were present in the vaginal or urethral secretions, before, during, and at the completion of treatment in all 16 cases, and 10 patients ( 5 men and 5 women) had trichomonads in the urine, before, during, and after treatment. In 10 cases the urine was investigated for antitrichomonal activity at the end of the course of treatment, but no such activity could be demonstrated. Blood serum was examined for antitrichomonal activity in four cases, and no increased activity was detected during or at the completion of treatment.

Thus acinitrazole, although actively trichomonacidal in vitro (Table V), did not produce any therapeutic effect on trichomonal infections in men or women when given systemically in the dosage recommended. The drug has

TABLE V.-In-vitro Tests with Acinitrazole

\begin{tabular}{|c|c|c|c|c|c|c|}
\hline \multirow{2}{*}{$\begin{array}{c}\text { Final } \\
\text { Concentration }\end{array}$} & \multicolumn{2}{|c|}{ After 1 Hour } & \multicolumn{2}{|c|}{ After 6 Hours } & \multicolumn{2}{|c|}{ After 24 Hours } \\
\hline & $\begin{array}{l}\text { Micro. } \\
\text { Exam. }\end{array}$ & Culture & $\begin{array}{l}\text { Micro. } \\
\text { Exam. }\end{array}$ & Culture & $\begin{array}{l}\text { Micro. } \\
\text { Exam. }\end{array}$ & Culture \\
\hline $\begin{array}{l}50 \mathrm{mg} . / \mathrm{ml} . \\
5.5 " \\
0.5 \\
\text { Control .. }\end{array}$ & $\bar{z}$ & $\bar{z}$ & $\bar{z}$ & $\bar{z}$ & $\overline{\bar{z}}$ & $\bar{z}$ \\
\hline
\end{tabular}


been made available to practitioners and widely advertised in the medical press, and it seems very unfortunate that this should have been done without detailed clinical trials to confirm the claims made for this preparation.

\section{Summary}

Treatment of trichomonal infections by local applications has proved unsatisfactory and the nature of the disease is probably such that treatment will continue to be unsatisfactory until a remedy is found which is effective when administered systemically.

An antibiotic, trichomycin, which has not been marketed in Britain and which has pronounced trichomonacidal activity in vitro, was supplied for investigation. Groups of patients were treated locally, systemically, and with combined local and systemic treatment. Local treatment was not satisfactory in preventing relapse and was less effective than the standard remedy, acetarsol. Systemic treatment was ineffective in eradicating the infection in 44 cases, and tests for antitrichomonal activity were negative in blood serum from six of these patients and in urine from 12.

Acinitrazole, which is also an effective trichomonacidal drug in vitro, was without therapeutic activity in 35 cases treated systemically. Samples of blood serum from four patients and urine from 10 patients showed no antitrichomonal activity at the end of the course of treatment.

A plea is made that new drugs should not be put on the market and advertised to physicians until adequate trials have been carried out and the results confirmed on repetition.

We thank Mr. A. J. King for permission to publish these results and Miss Joan Whittington and Dr. J. E. Middleton for the laboratory investigations. We also thank Dr. G. R. Fryers, of Messrs. Wyeth and Bro. Ltd., for arranging for the supplies of trichomycin and Messrs. Ward, Blenkinsop and Co. Ltd. for supplying acinitrazole. Part of this work was done on a grant from the United States Public Health Department on behalf of the working party on non-specific urethritis of the Medical Research Council.

\section{REFERENCES}

Bushby, S. R. M., Catterall, R. D., and Williamson, M. (1955). British Medical Journal, 1, 78

and Copp, F. C. (1955). J. Pharm. Pharmacol., 7, 112.

Cuckler, A. C., Kupferbers, A. B., and Millman, N. (1955). Antibiot. and Chemother.. 5, 540.

Hosoya, S., Komatsu, N., Soeda, M., and Sonoda, Y. (1952). Jap. J. exp. Med., 22, 505 .

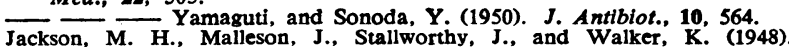
Problems of Fertility in General Practice. Hamilton, London.

Kean, B. H. (1955). Amer. J. Obstet. Gynec., 70, 397.

Magara, M., Mittono, H., and Senda, T. (1955). Antibiot. Med., 1, 394.

Plentyl, A. A., Gray, M. J., Neslen, E. D., and Delali, S. J. (1956). Amer. J. Obstet. Gynec., $71,116$.

\section{Medical Memorandum}

\section{Stab Wound of Heart with External Bleeding and Tamponade; Suture; Recovery}

Reports of successful surgical treatment of stab wounds of the heart are extremely rare in British literature, only four having been published in recent years. The following case presented certain features differing from those previously recorded.

\section{Case Report}

A married woman aged 25 was admitted to hospital on August 23, 1953, having sustained a stab wound of the praecordium with a pocket-knife half an hour previously. She was extremely shocked, having bled copiously externally, though the wound itself was small. She seemed too ill for radiological examination, but physical examination revealed no evidence of intrapleural bleeding or pneumothorax. There was a suggestion of jugular distension, but external bleeding seemed sufficient to account for the degree of shock. She was given 2 pints $(1,140 \mathrm{ml}$.) of dextran followed by 2 pints $(1,140 \mathrm{ml}$.) of blood in three hours. Her pulse became perceptible and was paradoxical: blood pressure was $75 \mathrm{~mm}$. systolic, no diastolic reading being obtainable. Jugular distension was now definite, and there was slight peripheral cyanosis. Haemopericardium with tamponade was diagnosed; operation was decided upon and was begun four hours after admission.

Operation.-The incision was L-shaped, centred on the stab wound, which was excised. The fourth left costal cartilage, which was found to have been severed, was resected, and the pleura was entered; it contained no blood, but the pericardium was bulging, blue, and tense. On opening the pericardium much clot and fluid blood was evacuated; a $\frac{3}{4}$-in. $(2-\mathrm{cm}$.) linear wound on the pulmonary conus of the right ventricle was spouting blood during each systole. The heart was "palmed" in the left hand, the thumb and index compressing and controlling the wound on the anterior aspect (Sauerbruch and O'Shaughnessy, 1937). Three silk sutures tied without tension effected satisfactory closure. The pericardium was loosely approximated with interrupted catgut, and the chest wall was closed in layers, with closed drainage of the pleura for 24 hours. Immediately after closure of the heart wound the blood pressure rose to $110 / 70$, and remained at this level without further transfusion.

The post-operative course was relatively uneventful; a slight pericardial effusion developed on the fifth day, and disappeared after a week's bed rest and systemic chloramphenicol. Six months later the patient was symptom-free and her electrocardiogram was within normal limits.

\section{COMMENT}

Contrary to popular belief, stab wounds of the heart are by no means always fatal. Although rare in Britain, this type of injury seems relatively common in America and Europe: several large series of cases treated surgically have been reported in American literature, with a survival rate of over $50 \%$. Patients reaching hospital alive must of necessity have small wounds; research (Brockman et al., 1953) has shown that large wounds are almost immediately fatal.

Blalock and Ravitch (1943) recommend transfusions at first, to raise the venous pressure and counteract tamponade. Aspiration of the pericardium is usually ineffective because of clot. Most authors recommend surgical intervention. The approach used in the above case was adequate, speedy to make, and simple to close. Wilson (1951) stresses the friability of ventricular muscle, not noted in the above case, and advises that the pericardium be left partly open to prevent recurrence of tamponade.

Most recorded cases have presented features of either tamponade or exsanguination; the first occurs if there is no free exit of blood from the pericardium, the second if such exit is present. The case reported here presented as one of exsanguination from external bleeding, and it was not until 5 pints $(2,840 \mathrm{ml}$.) of intravenous fluid had been given that signs of tamponade became apparent.

I thank Mr. C. M. Pearce, under whose care the patient was admitted, for permission to publish this case; Dr. E. A. Milner, whose skill as an anaesthetist made the operation possible; and the theatre and ward staff for their co-operation and unremitting care.

LEIGHTON C. BELL, F.R.C.S.,

Senior Surgical Registrar, Department of Thoracic Surgery, Frenchay Hospital, Bristol.

REFERENCES

Blalock, A., and Ravitch, M. M. (1943). Surgery, 14, 157. Brockman, H. L., Cooley D. A., and DeBakey, M. E. (1953). Surg. Forum, p. 108

Sauerbruch, F., and O'Shaughnessy, L. (1937). Thoracic Surgery. London. Wilson, G. S. M. (1951). British Medical Journal, 1, 511. 